\title{
Zinc-Mediated Hydroxyallylation of Aldehydes with Cyclopropanols: Direct Access to Vicinal anti-sec,tert-Diols via Enolized Homoenolate
}

\author{
Yoshiya Sekiguchi† and Naohiko Yoshikaił ${ }^{+, * *}$ \\ 'Division of Chemistry and Biological Chemistry, School of Physical and Mathematical Sciences, Nanyang Technological \\ University, Singapore 637371, Singapore \\ ‡Graduate School of Pharmaceutical Sciences, Tohoku University, 6-3 Aoba, Aramaki, Aoba-ku, Sendai 980-8578, Japan
}

\begin{abstract}
Direct and diastereoselective synthesis of vicinal anti-sec,tert-diols has been achieved by zinc-mediated $\alpha$ hydroxyallylation of aldehydes with cyclopropanols. The reaction features the action of zinc enolized homoenolate, formed via ring opening of zinc cyclopropoxide and enolization of the resulting homoenolate, as $\gamma$-oxyallyl nucleophile toward the carbonyl electrophile, which stands in contrast to the previously described enolate mode of the same species. A bicyclic chairlike transition state wherein the aldehyde substituent favorably occupies the psuedoaxial position is proposed to account for the anti selectivity.
\end{abstract}

The vicinal diol motif is prevalent in biologically active natural products and synthetically valuable intermediates, and hence its stereoselective construction represents a long-standing challenge in synthetic organic chemistry. Among various approaches to vicinal diols, the addition of $\gamma$-alkoxyallylmetal species to aldehydes ( $\alpha$-alkoxyallylation) has received considerable attention, as it provides diols bearing a synthetically versatile olefin moiety. ${ }^{1}$ However, despite the advancement in this reaction manifold through continuous development of new approaches to the requisite alkoxyallylmetal nucleophile, ${ }^{2} \alpha$-alkoxylallylation reactions that allow for the diastereocontrolled synthesis of sterically congested, sec,tert-diols remain scarce. ${ }^{3}$ Marek reported carbocupration/zinc homologation of ynol ethers as a means to generate $(E)$-configured $\alpha$-alkoxyallylzinc species, which reacted with aldehydes to afford syn-sec,tert-diols (Scheme 1a). ${ }^{4}$ More recently, Krische disclosed an enantioselective ruthenium-catalyzed reductive coupling of alkoxyallene and aldehyde via $(Z)$-configured $\alpha$-alkoxyallylruthenium species, which also afforded syn-diol products (Scheme $1 \mathrm{~b}) .^{5}$ Besides the need for deprotection of the alkoxy groups, a common limitation in these reactions concerns the scope of the $\alpha$ substituent in the allylmetal species. Marek's approach was limited by the scope of organocopper reagents capable of carbocupration $(\mathrm{R}=$ primary alkyl), whereas Krische's method employed only $\alpha$-methylalkoxyallene due to the difficulty in the preparation of differently substituted alkoxyallenes. In terms of direct access to unprotected diols, another notable approach is the pinacol-type reductive coupling between enone and aldehyde. Following the seminal report by Takai on a $\mathrm{Cr}(\mathrm{II}) / \mathrm{Me}_{3} \mathrm{SiCl}-$ mediated process, ${ }^{6}$ Loh described a $\mathrm{Zn} / \mathrm{InCl}_{3}$ mediated coupling in an aqueous media, where the enone was supposed to be converted to $\alpha$-oxyallylzinc species bearing indium(III) (Scheme 1c). ${ }^{7}$ However, the reaction displayed significantly varying and often moderate diastereoselectivity and was again limited in the scope of the $\alpha$-substituent (Et or $\mathrm{Me})$.
Herein, we disclose a direct and diastereoselective synthesis of anti-sec,tert-diols via zinc-mediated hydroxylallylation of aldehydes with cyclopropanols (Scheme 1d). The reaction is promoted using the combination of $\mathrm{Et}_{2} \mathrm{Zn}$ and 2,2'-bipyridine (bpy) at room temperature, engaging a variety of 1 -substituted cyclopropanols and bicyclic cyclopropanols as well as aromatic and aliphatic aldehydes. The present reaction features the action of enolized homoenolate, ${ }^{8-11}$ formed through $\mathrm{Et}_{2} \mathrm{Zn}$-mediated ring-opening of cyclopropanol and subsequent enolization of the resulting homoenolate, as a stereodefined $\alpha$-oxyallylzinc nucleophile toward the aldehyde. The complementary antiselectivity of the reaction was ascribed to a bicyclic chairlike transition state of allylation, where the aldehyde substituent prefers to occupy the pseudoaxial position.

Since the seminal report of Cha and coworkers, ${ }^{12}$ zinc homoenolate (II) generated by ring opening of zinc cyclopropoxide (I) has proved to serve as a $\beta$-carbonyl nucleophile in allylation, ${ }^{12}$ acylation, ${ }^{13}$ alkynylation, ${ }^{14}$ and conjugate addition (Scheme 1d, mode 1). ${ }^{15-18}$ Recently, we reported a zinc-catalyzed $\beta$-functionalization of cyclopropanols with Morita-Baylis-Hillman carbonates, which involves enolization of II into enolized homoenolate III, its reaction as enolate toward the electrophile, and ring closure of the homoenolate to cyclopropoxide (mode 2). ${ }^{8}$ Following this finding, we became interested in the potential reactivity of III as an $\alpha$-oxyallyl nucleophile (mode 3 ). Prompted by this conjecture and the aforementioned importance of vicinal diols, we set out to explore the reaction of 1-phenylcyclopropanol (1a) and benzaldehyde (2a).

Scheme 1. Aldehyde Allylation Approaches to Vicinal sec,tert-Diols 
(a) Marek et al.

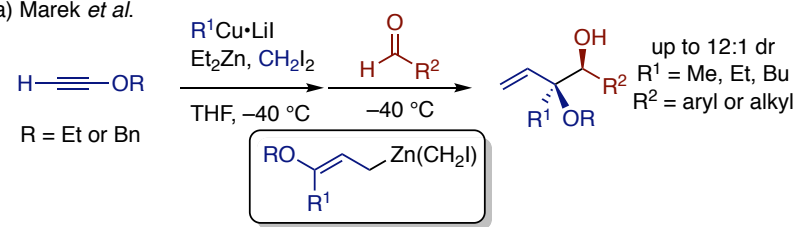

(b) Krische et al.
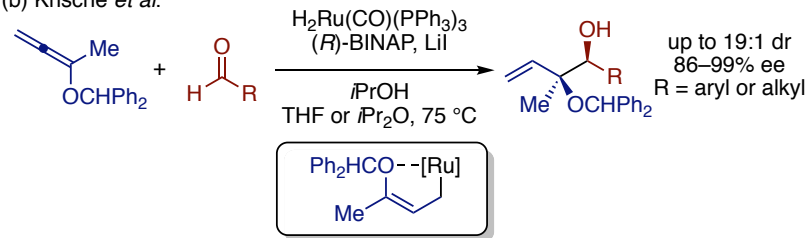

(c) Loh et al.

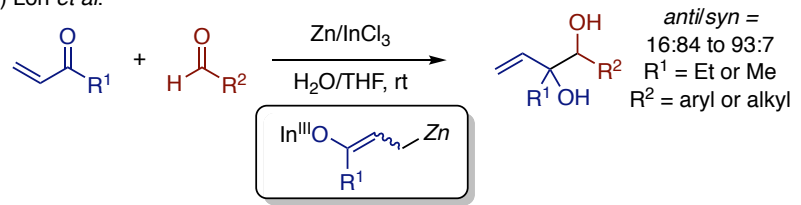

(d) This work

$$
\text { (2) }
$$

The reaction between 1a and 2a in the presence of $\mathrm{Et}_{2} \mathrm{Zn}(2$ equiv) proceeded smoothly in DMSO at $80^{\circ} \mathrm{C}$ in $1 \mathrm{~h}$, affording the anti-diol 3aa in 73\% yield with diastereoselectivity of 3:1 (Table 1, entry 1). Notably, we did not observe alternative coupling products arising from the mode 1 and mode 2 reactivities. The relative configuration of $\mathbf{3 a a}$ was confirmed by comparison with the opposite diastereomer obtained by the addition of vinyl Grignard reagent to $\alpha$-hydroxyketone. ${ }^{19}$ Unlike our previous reports on catalytic zinc homoenolate and enolized homoenolate reactions, ${ }^{8,15}$ the reaction was also feasible in less-coordinating THF, furnishing 3aa with improved diastereoselectivity (entry 2), while noncoordinating toluene completely shut down the reaction (entry 3 ). Although the reaction in THF failed at $23{ }^{\circ} \mathrm{C}$ (entry 4), the addition of coordinating nitrogen additives ( 2 equiv) was found to restore the reactivity, among which bpy gave the best results in terms of the yield and the diastereoselectivity (entries 5-8). The amount of bpy could be reduced to 1 equiv without problem (entry 9), while further reduction led to a more sluggish reaction (entry 10). Lowering the amount of $\mathrm{Et}_{2} \mathrm{Zn}$ resulted in a decrease in the diastereoselectivity (entry 11 ).

Table 1. $\mathbf{E t}_{2} \mathrm{Zn}$-Mediated Hydroxyallylation of Benzaldehyde (2a) with 1-Phenylcyclopropanol (1a) ${ }^{a}$

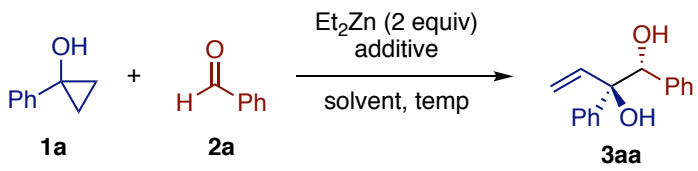

\begin{tabular}{llllll} 
entry & $\begin{array}{l}\text { additive } \\
\text { (equiv) }\end{array}$ & solvent & $\begin{array}{l}T \\
\left({ }^{\circ} \mathrm{C}\right)\end{array}$ & $\begin{array}{l}\text { yield } \\
(\%)^{b}\end{array}$ & $\mathrm{dr}^{c}$ \\
\hline 1 & - & DMSO & 80 & 73 & $3: 1$ \\
2 & - & THF & 80 & 66 & $8: 1$ \\
3 & - & toluene & 80 & 0 & - \\
4 & - & THF & 23 & 0 & - \\
5 & bpy (2) & THF & 23 & 73 & $11: 1$ \\
6 & pyridine (2) & THF & 23 & 17 & $7: 1$ \\
7 & TMEDA (2) & THF & 23 & 64 & $7: 1$ \\
8 & DABCO (2) & THF & 23 & 79 & $3: 1$ \\
9 & bpy (1) & THF & 23 & 71 & $11: 1$ \\
10 & bpy (0.5) & THF & 23 & 53 & $16: 1$ \\
$11^{d}$ & bpy (1) & THF & 23 & 64 & $4: 1$
\end{tabular}

${ }^{a}$ The reaction was performed using $0.05 \mathrm{mmol}$ of $1 \mathrm{a}$ and 0.075 mmol of $2 \mathrm{a}$ in solvent $(0.33 \mathrm{M})$. The reaction time was $1 \mathrm{~h}$ (entries 1-3) or $12 \mathrm{~h}$ (entries 4-11). ${ }^{b}$ Determined by GC using mesitylene as an internal standard. ${ }^{c}$ Determined by ${ }^{1} \mathrm{H}$ NMR of the crude mixture. ${ }^{d} 1$ equiv of $\mathrm{Et}_{2} \mathrm{Zn}$ was used.

With the optimized conditions (Table 1, entry 9) in hand, we first explored the reaction of various cyclopropanols with $\mathbf{2 a}$ (Scheme 2). A series of 1-(hetero)arylcyclopropanols participated in the hydroxyallylation to afford the corresponding anti-diols 3aa-3ha in moderate to good yields with tolerance to electron-donating and -withdrawing substituents and thienyl group. As a general trend, higher diastereoselectivities were observed with electron-rich aryl groups ( $>20: 1$, see 3ba and 3ca) than with electron-deficient aryl groups (6:1, see 3da-3fa). The model reaction could be performed on a $6 \mathrm{mmol}$ scale, affording 3aa in $64 \%$ yield with 12:1 dr. 1-Alkylcyclopropanols bearing a primary or secondary alkyl group also reacted with $\mathbf{2 a}$ at an elevated temperature $\left(80^{\circ} \mathrm{C}\right)$ to afford the corresponding diols 3ia-3la in moderate yields with good to high diastereoselectivities. Bicyclic cyclopropanols $\mathbf{1 m}$ and $\mathbf{1 n}$ also successfully participated in the reaction to afford the diols 3ma and 3na. The structure of the latter was confirmed by X-ray crystallographic analysis.

Scheme 2. Hydroxyallylation of Benzaldehyde (2a) with Various Cyclopropanols ${ }^{a}$ 


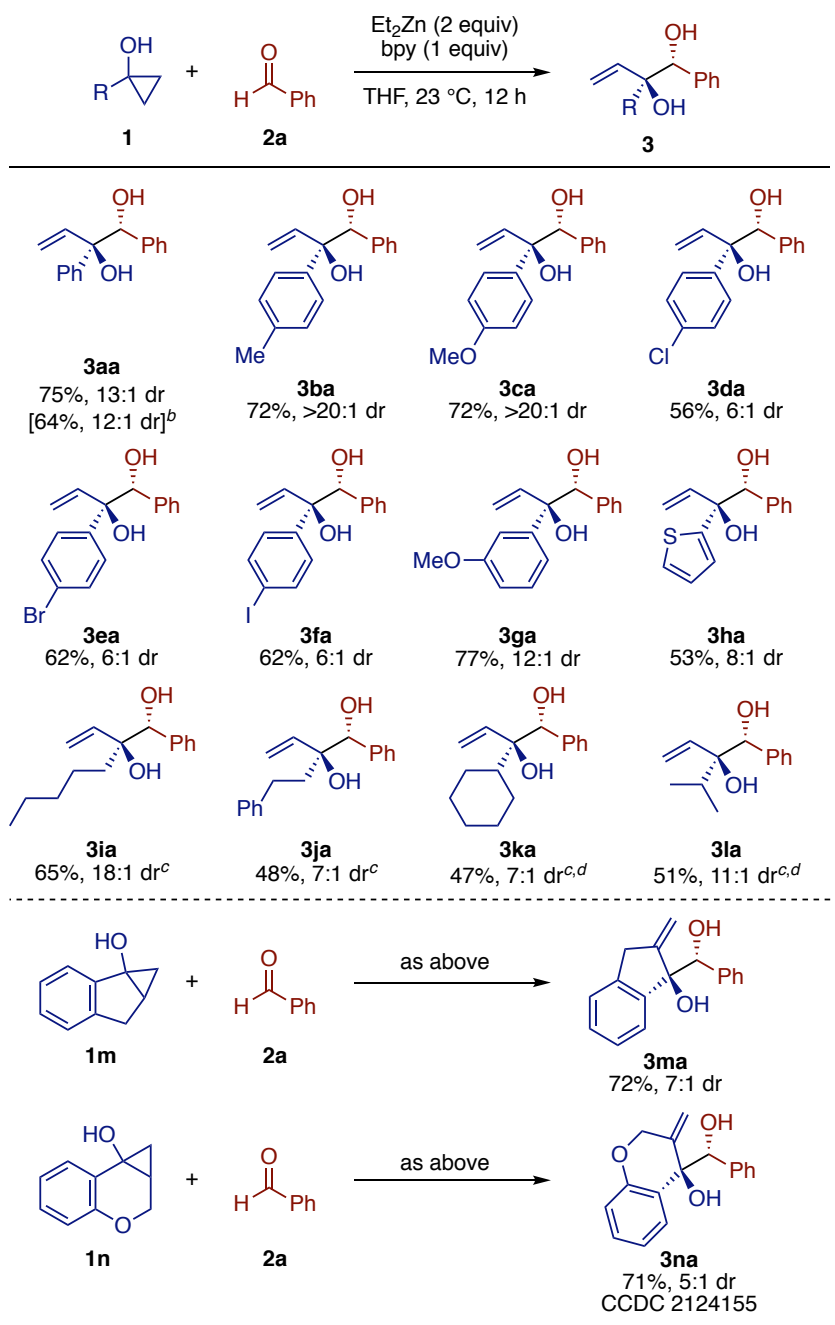

${ }^{a}$ The reaction was performed on a $0.3 \mathrm{mmol}$ scale. ${ }^{b}$ The yield of a $6 \mathrm{mmol}$ scale reaction is shown in the parentheses. ${ }^{c}$ The reaction was performed at $80^{\circ} \mathrm{C}$ for $1 \mathrm{~h}$. ${ }^{d}$ The reaction was performed in DMSO in the absence of bpy.

We next explored the reaction of $\mathbf{1 a}$ with various aldehydes (Scheme 3). A series of (hetero)aryl aldehydes proved to be good substrates, affording the corresponding products $\mathbf{3 a b}-\mathbf{3 a j}$ in moderate to good yields with moderate to high diastereoselectivities. Electron-rich aldehydes reacted smoothly under the standard conditions with high diastereoselectivities (see 3ab-3ad). On the other hand, the reactions of electrondeficient aldehydes had to be carried out at $0{ }^{\circ} \mathrm{C}$ to ensure good diastereoselectivity (see 3ae and 3af). The reaction of 3-methyl2-butenal afforded the desired 1,2-addition product 3ak. Primary alkyl aldehydes also participated in the reaction at $80{ }^{\circ} \mathrm{C}$ to give the diols 3al and 3am with good diastereoselectivity. Interestingly, the reactions of secondary alkyl aldehydes produced the desired vicinal diols 3an-3ap as the major products with excellent diastereoselectivity, which were accompanied by 2-(1-hydroxyalkyl)-1phenylcyclopropanols 4an-4ap, as a result of $\beta$ functionalization of $\mathbf{1 a}$ (i.e., mode 2 reactivity). Likewise, the reaction of nonracemic (-)-menthyl 3-carboxaldehyde afforded the adduct $\mathbf{3 a q}$ as the dominant isomer in $50 \%$ yield, ${ }^{20}$ while the corresponding cyclopropanol-type product was also obtained in $34 \%$ yield as a mixture of more than three isomers (data not shown). Pivalaldehyde afforded the cyclopropanol 4ar as the exclusive product, whose relative configuration was determined by X-ray crystallographic analysis. It should be noted that Matsubara reported diastereoselective synthesis of 2-(1hydroxyalkyl)-1-alkylcyclopropanols from $\alpha, \beta$-epoxyketones and bis(iodozincio)methane ${ }^{21}$ as well as their zincate-mediated rearrangement into vicinal diols. ${ }^{22}$ The mechanistic connection between the latter and the present reactions remains to be seen.

Scheme 3. Hydroxyallylation of Various Aldehydes with 1Phenylcyclopropanol (1a) ${ }^{a}$

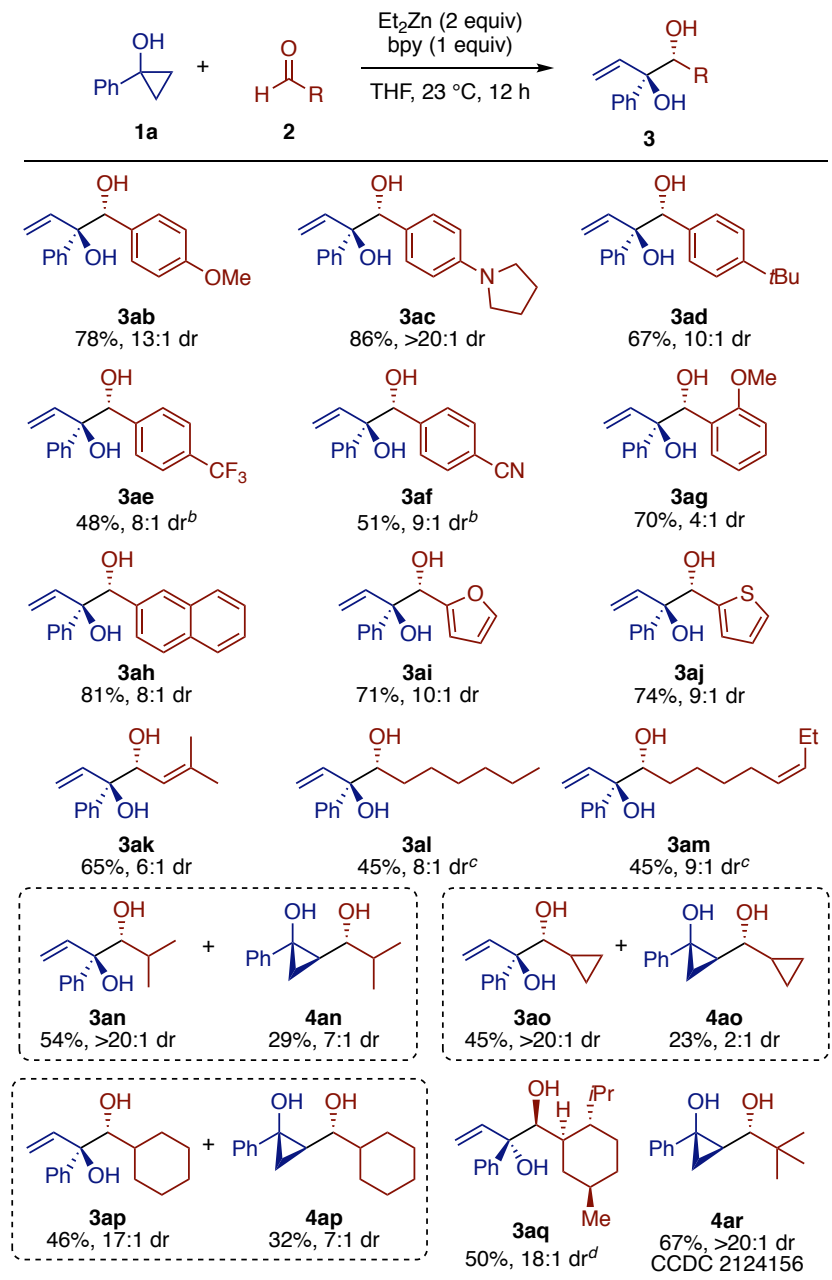

${ }^{a}$ The reaction was performed on a $0.3 \mathrm{mmol}$ scale. ${ }^{b}$ The reaction was performed at $0{ }^{\circ} \mathrm{C}$ for $24 \mathrm{~h}$. ${ }^{c}$ The reaction was performed at $80{ }^{\circ} \mathrm{C}$ using 0.1 equiv of bpy. ${ }^{d}$ The ratio of the major diastereomer and the rest indicated from ${ }^{1} \mathrm{H}$ NMR analysis of the crude product. The cyclopropanol-type product such as 4ap was also obtained as a mixture of diastereomers ( $34 \%$ yield).

Having explored the scope and limitation of the present hydroxyallylation of aldehydes, we briefly probed the possibility of its extension to a ketone electrophile and an enantioselective variant. First, the $\mathrm{Et}_{2} \mathrm{Zn}$-mediated reaction between $1 \mathbf{a}$ and highly strained cyclobutanone (2s) was found to proceed in DMSO at $80^{\circ} \mathrm{C}$, affording the tert,tert-diol 3as in $47 \%$ yield (Scheme $4 a$ ). Meanwhile, an attempted reaction of 1a with less strained cyclopentanone resulted in a complex mixture. Next, the model reaction between $1 \mathbf{a}$ and $\mathbf{2 a}$ in the presence of cinchonidine using dioxane as the solvent took place with moderate enantioselectivity of 84:16 er (Scheme 5b). Other chiral additives such as amino alcohol and bisoxazoline 
derivatives tested thus far induced lower enantioselectivities (see Scheme S1).

Scheme 4. (a) Addition to Cyclobutanone and (b) Preliminary Enantioselective Variant

(a)

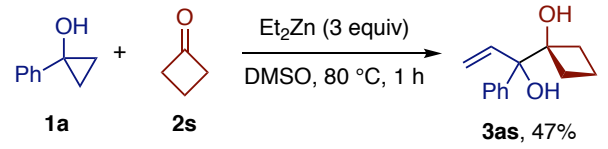

(b) $\quad \mathrm{Et}_{2} \mathrm{Zn}$ (2 equiv)

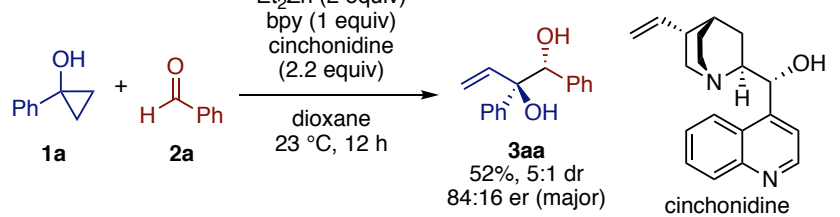

Showing consistently good anti-selectivity, the present reaction complements the previously reported syn-selective alkoxyallylations (Scheme 1a, b). To probe the origin of this diastereoselectivity, we performed DFT calculations on model reactions between enolized homoenolates and aldehydes (Figure 1a). ${ }^{23}$ First, $(Z)$-configured enolized homoenolate $(Z)$ $\mathbf{C P}$, which is derived from 1a and features chelation between the enolate oxygen and homoenolate zinc, was calculated to be far more stable $\left(\Delta \Delta G=7.4 \mathrm{kcal} \mathrm{mol}^{-1}\right)$ than its $(E)$-counterpart $((E)-\mathbf{C P})$. Despite the strong chelation, boat-like transition states for the addition of (Z)-CP to $\mathbf{2 a}$ were not located. Instead, it was found to form bicyclic chairlike transition states anti-TS1 and $s y n$-TS1, where the aldehyde oxygen was coordinated not only by the homoenolate zinc but also by the enolate zinc. With the aldehyde phenyl group at the psuedoaxial position, anti-TS1 was lower in energy than syn-TS1 by $1.0 \mathrm{kcal} \mathrm{mol}^{-1}$, which was qualitatively in line with the observed selectivity toward anti3aa. The same trend was also found with other TSs that modelled substrate combinations such as $\mathbf{1 a}$ /acetaldehyde and 1-methylcyclopropanol/2a (see Figure S6 and S7). Thus, we suggest that unfavorable two gauche interactions encountered with psudoequatorial placement of the aldehyde substituent, as described by Marek, ${ }^{24}$ account for the generally observed anti selectivity of the present reaction.

Besides the diastereoselectivity in hydroxyallylation, we also probed the origin of the diastereoselectivity in the formation of the 1,3-diol such as 4ar (Figure 1b). Notably, in the aldol reaction step, the bulky tert-butyl group displayed preference for occupying the pseudoaxial position in the chairlike TS (antiTS2) to avoid the gauche interaction with the zinciomethyl group in the alternative TS (syn-TS2). Following this aldol step, the subsequent ring closure would occur while avoiding the steric clash between the phenyl group and the alkoxide moiety, thus setting the relative configuration of the cyclopropane substituents. Compared with a related synthesis of 2-(1hydroxyalkyl)-1-alkylcyclopropanol via $\mathrm{Cr}$ (II)-mediated coupling of enone and aldehyde by Takai, ${ }^{25}$ which also involves aldol and cyclopropanation steps but with moderate diastereoselectivity with respect to the former, the high diastereoselectivity may be ascribed to the fixed (Z)configuration of enolized homoenolate. (a)
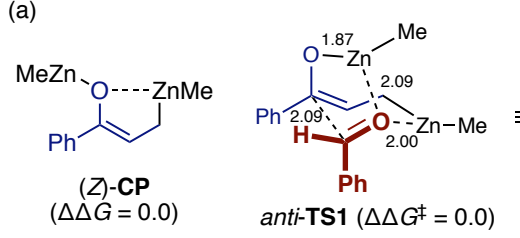

anti-TS1 $\left(\Delta \Delta G^{\ddagger}=0.0\right)$ leading to anti-3aa
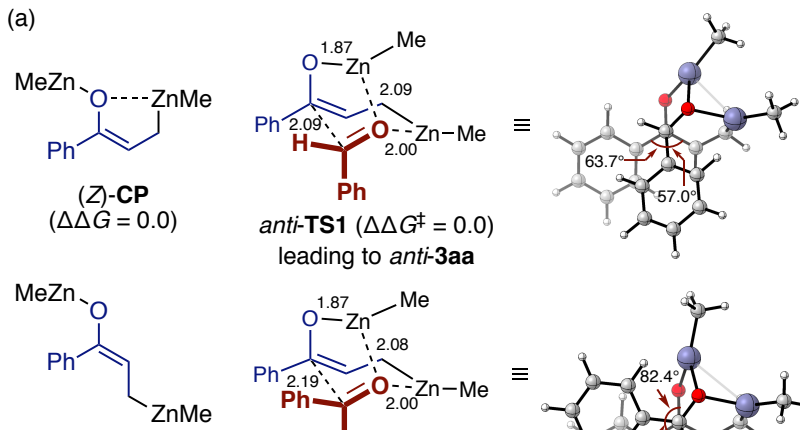

(E)-CP

$(\triangle \triangle G=7.4)$
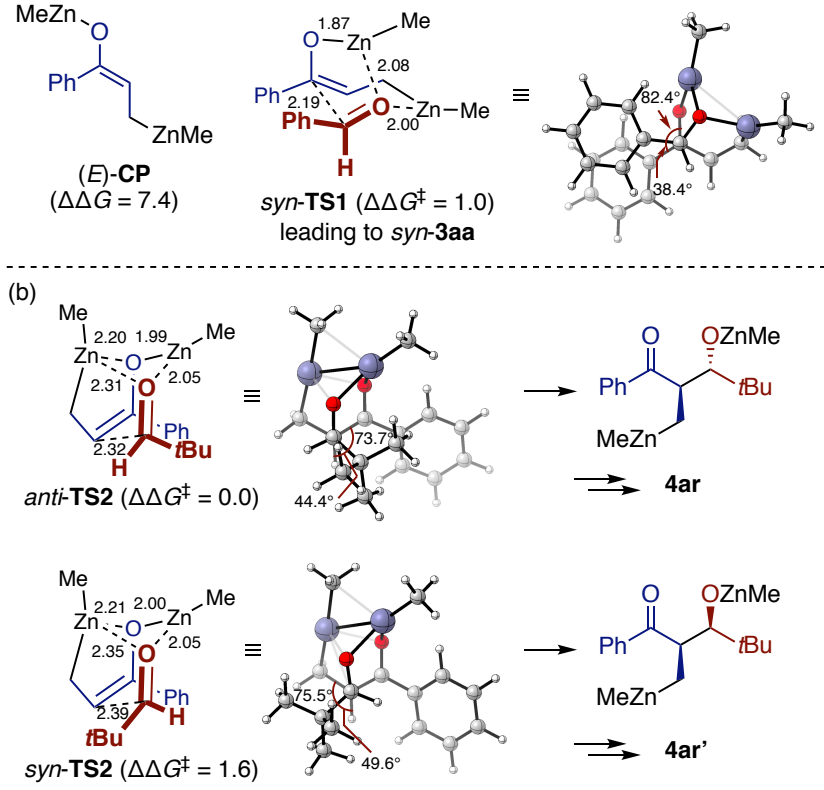

Figure 1. Results of DFT calculations (M062X-SMD(THF)/6$31+\mathrm{G}(\mathrm{d}, \mathrm{p}) / / \mathrm{M} 062 \mathrm{X} / 6-31 \mathrm{G}(\mathrm{d}))$ : (a) Comparision of $(Z)-$ and $(E)-$ configured enolized homoenolate and transition states of hydroxyallylation leading to the major and minor diastereomers of 3aa. (b) Transition states of aldol reaction leading to the major and minor diastereomers of 4ar.

In summary, we have developed a zinc-mediated hydroxyallylation of aldehydes with cyclopropanols for the synthesis of vicinal anti-sec,tert-diols under operationally simple and mild conditions, which complements the existing alkoxyallylation reactions. Featuring the reaction mode of enolized homoenolate as $\gamma$-oxyallyl nucleophile, the present hydroxyallylation further expands the utility of cyclopropanols beyond well-explored homoenolate and $\beta$-keto radical transformations. ${ }^{18}$ The overall transformation (i.e., cyclopropanol and aldehyde into vicinal diol) is thermodynamically favorable and hence, in theory, could be made catalytic and enantioselective. Further investigations into the reaction chemistry of homoenolate and enolized homoenolate are currently underway in our laboratory. ${ }^{26}$

\section{ASSOCIATED CONTENT}

\section{Supporting Information}

The Supporting Information is available free of charge on the ACS Publications website.

Experimental procedures and characterization data for all the new products (PDF).

\section{Accession Codes}

CCDC 2124155-2124156 contain the supplementary crystallographic data for this paper. These data can be obtained free of charge via www.ccdc.cam.ac.uk/data request/cif, or by emailing data request@eccdc.cam.ac.uk, or by contacting The 
Cambridge Crystallographic Data Centre, 12 Union Road, Cambridge CB1, 1EZ, UK; fax: +44 1223336033.

\section{AUTHOR INFORMATION}

\section{Corresponding Author}

*naohiko.yoshikai.c5@tohoku.ac.jp

\section{Notes}

The authors declare no competing financial interests.

\section{ACKNOWLEDGMENT}

This work was supported by the Ministry of Education (Singapore) and Nanyang Technological University (RG101/19) and JSPS KAKENHI (Grant No. 20K23375). The DFT calculations were performed using supercomputing resources at Cyberscience Center, Tohoku University. We thank Dr. Yongxin Li (Nanyang Technological University) for his assistance with the X-ray crystallographic analysis.

\section{REFERENCES}

(1) Lombardo, M.; Trombini, C. $\alpha$-Hydroxyallylation Reaction of Carbonyl Compounds. Chem. Rev. 2007, 107, 3843-3879.

(2) Schafers, F.; Quach, L.; Schwarz, J. L.; Saladrigas, M.; Daniliuc, C. G.; Glorius, F. Direct Access to Monoprotected Homoallylic 1,2-Diols via Dual Chromium/Photoredox Catalysis. ACS Catal. 2020, 10, 11841-11847.

(3) For an alternative approach to the same scaffold, see: Chen, M.; Handa, M.; Roush, W. R. Enantioselective Synthesis of 2Methyl-1,2-syn- and 2-Methyl-1,2-anti-3-Butenediols via Allene Hydroboration-Aldehyde Allylboration Reaction Sequences. J. Am. Chem. Soc. 2009, 131, 14602-14603.

(4) Mejuch, T.; Botoshansky, M.; Marek, I. Combined Carbometalation-Zinc Homologation-Allylation Reactions as a New Approach for Alkoxyallylation of Aldehydes. Org. Lett. 2011, 13, 3604-3607.

(5) Xiang, M.; Pfaffinger, D. E.; Ortiz, E.; Brito, G. A.; Krische, M. J. Enantioselective Ruthenium-BINAP-Catalyzed Carbonyl Reductive Coupling of Alkoxyallenes: Convergent Construction of syn-sec,tert-Diols via (Z)- $\sigma$-Allylmetal Intermediates. J. Am. Chem. Soc. 2021, 143, 8849-8854.

(6) (a) Takai, K.; Morita, R.; Toratsu, C. Stereoselective Cross Pinacol-Type Coupling between $\alpha, \beta$-Unsaturated Ketones and Aldehydes Mediated by Chromium(II) and $\mathrm{R}_{3} \mathrm{SiCl}$. Angew Chem. Int. Ed. 2001, 40, 1116-1119. (b) Takai, K.; Morita, R.; Matsuhita, H.; Toratsu, C. Cross-Pinacol-Type Coupling Reactions between $\alpha, \beta$-Unsaturated Ketones and Aldehydes with Low-Valent Metals. Chirality 2003, 15, 17-23.

(7) Yang, Y. S.; Shen, Z. L.; Loh, T. P. Zn/ $\mathrm{InCl}_{3}$-Mediated Pinacol Cross-Coupling Reactions of Aldehydes with $\alpha, \beta$-Unsaturated Ketones in Aqueous Media. Org. Lett. 2009, 11, 2213-2215.

(8) Sekiguchi, Y.; Yoshikai, N. Zinc-Catalyzed $\beta$ Functionalization of Cyclopropanols via Enolized Homoenolate. J. Am. Chem. Soc. 2021, 143, 18400-18405.

(9) Hirayama, T.; Oshima, K.; Matsubara, S. Preparation of Enolate-Homoenolate Species as $(Z)-\gamma$-Siloxyallylmetal Equivalents: Sequential 1,4-Addition of Bis(iodozincio)methane to 1,4-Dicarbonylbutenes and Cyclopropanation. Angew. Chem. Int. Ed. 2005, 44, 3293-3296.

(10) Ryu, I.; Nakahira, H.; Ikebe, M.; Sonoda, N.; Yamato, S.; Komatsu, M. Chelation-Aided Generation of Ketone $\alpha, \beta-$ Dianions and Their Use as Copper Ate Complexes. Unprecedented Enolate Intervention in the Conjugate Addition to Enones. J. Am. Chem. Soc. 2000, 122, 1219-1220.

(11) Huang, W.; Meng, F. Cobalt-Catalyzed Diastereo- and Enantioselective Hydroalkylation of Cyclopropenes with Cobalt Homoenolates. Angew. Chem. Int. Ed. 2021, 60, 26942698.
(12) Das, P. P.; Belmore, K.; Cha, J. K. $\mathrm{S}_{\mathrm{N}} 2$ ' Alkylation of Cyclopropanols via Homoenolates. Angew. Chem. Int. Ed. 2012, 51, 9517-9520.

(13) Parida, B. B.; Das, P. P.; Niocel, M.; Cha, J. K. C-Acylation of Cyclopropanols: Preparation of Functionalized 1,4-Diketones. Org. Lett. 2013, 15, 1780-1783.

(14) Murali, R. V. N. S.; Rao, N. N.; Cha, J. K. C-Alkynylation of Cyclopropanols. Org. Lett. 2015, 17, 3854-3856.

(15) Sekiguchi, Y.; Yoshikai, N. Enantioselective Conjugate Addition of Catalytically Generated Zinc Homoenolate. J. Am. Chem. Soc. 2021, 143, 4775-4781.

(16) For another reaction mode of zinc homoenolate as amphoteric species, see: Mills, L. R.; Arbelaez, L. M. B.; Rousseaux, S. A. L. Electrophilic Zinc Homoenolates: Synthesis of Cyclopropylamines from Cyclopropanols and Amines. J. Am. Chem. Soc. 2017, 139, 11357-11360.

(17) For selected reviews on homoenolate reactions, see: (a) Sekiguchi, Y.; Yoshikai, N. Metal-Catalyzed Transformations of Cyclopropanols via Homoenolates. Bull. Chem. Soc. Jpn. 2021, 94, 265-280. (b) Mills, L. R.; Rousseaux, S. A. L. Modern Developments in the Chemistry of Homoenolates. Eur. J. Org. Chem. 2019, 2019, 8-26. (c) Kuwajima, I.; Nakamura, E. Metal Homoenolates from Siloxycyclopropanes. Top. Curr. Chem. 1990, 155, 1-39.

(18) For selected reviews on the synthetic utility of cyclopropanols, see: (a) McDonald, T. R.; Mills, L. R.; West, M. S.; Rousseaux, S. A. L. Selective Carbon-Carbon Bond Cleavage of Cyclopropanols. Chem. Rev. 2021, 121, 3-79. (b) Cai, X. P.; Liang, W. D.; Dai, M. J. Total Syntheses via Cyclopropanols. Tetrahedron 2019, 75, 193-208. (c) Nikolaev, A.; Orellana, A. Transition-Metal-Catalyzed C-C and C-X Bond-Forming Reactions Using Cyclopropanols. Synthesis 2016, 48, 17411768

(19) Wu, H.; Wang, Q.; Zhu, J. Organocatalytic Enantioselective Acyloin Rearrangement of $\alpha$-Hydroxy Acetals to $\alpha$-Alkoxy Ketones. Angew. Chem. Int. Ed. 2017, 56, 5858-5861.

(20) Spino, C.; Godbout, C.; Beaulieu, C.; Harter, M.; MweneMbeja, T. M.; Boisvert, L. p-Menthane-3-Carboxaldehyde: A Useful Chiral Auxiliary for the Synthesis of Chiral Quaternary Carbons of High Enantiomeric Purity. J. Am. Chem. Soc. 2004, 126, 13312-13319.

(21) Nomura, K.; Oshima, K.; Matsubara, S. Stereospecific and Stereoselective Preparation of 2-(1-Hydroxyalkyl)-1Alkylcyclopropanols from $\alpha, \beta$-Epoxy Ketones and Bis(iodozincio) Methane. Angew. Chem. Int. Ed. 2005, 44, 5860-5863.

(22) (a) Nomura, K.; Matsubara, S. A New Zincate-Mediated Rearrangement Reaction of 2-(1-Hydroxyalkyl)-1Alkylcyclopropanol. Chem. Eur. J. 2010, 16, 703-708. (b) Nomura, K.; Matsubara, S. Zincate-Mediated Rearrangement Reaction of 2-(1-Hydroxyalkyl)-1-Alkylcyclopropanol. Chem. Commun. 2009, 2212-2213.

(23) See the Supporting Information for computational details.

(24) Mejuch, T.; Gilboa, N.; Gayon, E.; Wang, H.; Houk, K. N.; Marek, I. Axial Preferences in Allylation Reactions via the Zimmerman-Traxler Transition State. Acc. Chem. Res. 2013, 46, 1659-1669.

(25) Toratsu, C.; Fujii, T.; Suzuki, T.; Takai, K. Cross-Coupling Reactions between $\alpha, \beta$-Unsaturated Ketones and Aldehydes with $\mathrm{CrCl}_{2}$ : Aldol Condensation and Cyclopropanol Formation. Angew. Chem. Int. Ed. 2000, 39, 2725-2727.

(26) (a) Yang, J.; Shen, Y.; Lim, Y. J.; Yoshikai, N. Divergent RingOpening Coupling between Cyclopropanols and Alkynes under Cobalt Catalysis. Chem. Sci. 2018, 9, 6928-6934. (b) Yang, J.; Sun, Q.; Yoshikai, N. Cobalt-Catalyzed Regio- and Diastereoselective Formal [3+2] Cycloaddition between Cyclopropanols and Allenes. ACS Catal. 2019, 9, 1973-1978. (c) Yang, J.; Sekiguchi, Y.; Yoshikai, N. Cobalt-Catalyzed Enantioselective and Chemodivergent Addition of Cyclopropanols to Oxabicyclic Alkenes. ACS Catal. 2019, 9, 5638-5644. (d) Sekiguchi, Y.; Lee, Y. Y.; Yoshikai, N. Nickel- 
Catalyzed Ring-Opening Allylation of Cyclopropanols via

Homoenolate. Org. Lett. 2021, 23, 5993-5997.

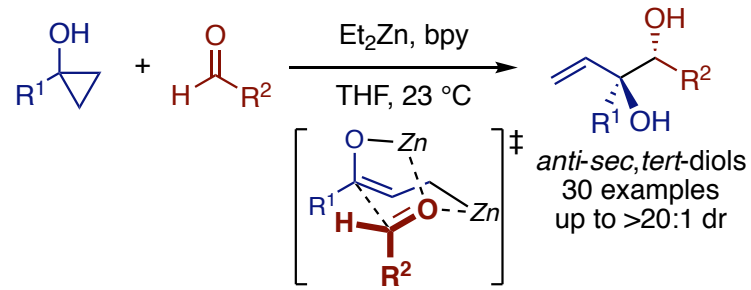

